\title{
Crystallization of copper(II) sulfate based minerals and MOF from solution: Chemical insights into the supramolecular interactions
}

\author{
M SINGH, D KUMAR, J THOMAS and A RAMANAN* \\ Department of Chemistry, Indian Institute of Technology, New Delhi 110016 \\ e-mail: aramanan $a$ chemistry.iitd.ac.in
}

\begin{abstract}
Crystallization of solids, molecular or non-molecular from solution is a supramolecular reaction. Nucleation of a lattice structure at supersaturation can be conceived to result from a critical nucleus, a high energy intermediate (supramolecular transition state). Conceptualization of a structure for the critical nucleus in terms of aggregation of tectons through non-covalent interactions provides chemical insights into the architecture of a solid. The retrosynthetic analysis of copper-based minerals and materials offers an elegant description for the crystal packing. It addresses the influence of the geometry, functionality and reactivity of copper tecton(s) in directing a specific supramolecular aggregation. The mechanistic approach provides guiding principles to chemists to account for the experimentally crystallized solids and a platform to practice structure-synthesis correlation. Rationalization of the same composition with different atomic arrangements (polymorphs), compositional variation leading to different pseudopolymorphs, degree of hydration (anhydrous to hydrated), water clusters, role of solvent, etc. can all be justified on molecular basis. Also, the method gives predictive components including directions to synthesize new solids. In a nutshell, the paper is an attempt to generalize the crystallization of inorganic solids from solution by recognizing supramolecular interactions between metal tectons and gain insights for designing new MOF.
\end{abstract}

Keywords. Crystallization; nucleation; supramolecular interaction; copper-based minerals; coordination polymer; MOF.

\section{Introduction}

Materials research for the past few decades have been dominated by $3 \mathrm{~d}$ transition metal based nonmolecular oxides, halides, chalcogenides owing to their rich structural chemistry and a range of electronic, magnetic, optical and catalytic properties. ${ }^{1,2}$ Most of these materials are obtained through conventional solid state route wherein the reaction is essentially diffusion-controlled leading to thermodynamically stable phases. However, in the recent past the focus has diverted towards another class of materials, organic inorganic hybrids ${ }^{3}$ that include coordination polymers (CP) and metal organic frameworks (MOF) wherein the hard properties of inorganic ceramics and the flexibility of soft organic matrix are being integrated to obtain functional materials. ${ }^{4-6}$ Unlike molecular synthesis, preparation of solids relies heavily on exploratory methods, and it is well-recognized that the complexity of the possibilities often defies predictability. ${ }^{7,8}$ In figure 1 we highlight the three major activities of the chemistry

\footnotetext{
*For correspondence
}

of materials namely synthesis, structure and property at the corners of a triangle. Structure-property relationship is widely investigated for the past few decades; Yaghi's reticular synthesis of MOF is a notable example. ${ }^{9,10}$ While structure-synthesis correlation is rarely attempted due to lack of suitable mechanisms, designing or engineering a crystal to exhibit a particular set of properties for example, porosity towards gas storage and separation still remains an elusive dream.

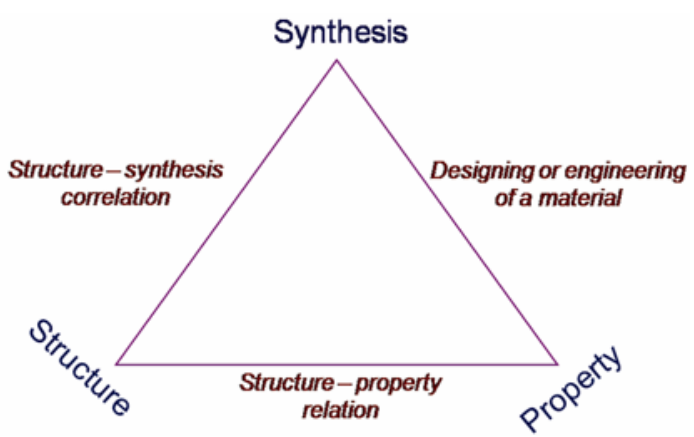

Figure 1. Three major activities of the chemistry of materials. 
With an objective to design zeolite mimics, several groups have exploited a synthetic strategy based on metal or metal cluster nodes coordinated through multidentate organic spacers. ${ }^{11}$ Almost all CPs and MOFs are synthesized in a self-assembly process in which soluble metal species are reacted with suitable organic ligands that chelate/coordinate with metal. The most commonly employed ligands are carboxylate, polypyridyl ligands, polyazaheteroaromatic ligands such as imidazolate, pyrazolate, triazolate, and tetrazolate. This class of ligands affords the ability to bridge metal sites and is readily derivatized to provide bridging ligands with additional functionality. Interestingly, in many cases a crystal is achieved 'by default' rather than 'by design'! ${ }^{12}$ For true design and crystal engineering of a framework, one needs to assess the occurrence of different topologies (nets, grids, chains, sheets, helices, etc.) and solid state architectures in terms of chemically reasonable molecules reacting in the solution from which the crystals nucleate and grow. The terms like 'self assembly', 'templating' and 'metal nucleation' frequently employed in the literature will become more meaningful if we can understand the supramolecular reaction mediated in a solvent around the phase transition and how the chemical variables $(\mathrm{pH}$, concentration, etc.) and external variables (temperature and pressure) influence the aggregation by the participating molecules. Almost five years ago we provoked a discussion by questioning 'How molecules turn into solids?' and responded by providing some intuitive mechanisms for the crystallization of selected MOFs. ${ }^{13}$ We further extended this mechanistic approach to many other systems including vanadates and molybdates and suggested molecular interpretation for the occurrence of water clusters, polymorphs, pseudopolymorphs, interpenetrated networks, hydration and solvation. ${ }^{14-19}$ Recently for the first time we employed the retrosynthetic analysis to interpret the packing of several minerals and materials crystallized from the system $\mathrm{CuCl}_{2}-\mathrm{H}_{2} \mathrm{O}-\mathrm{CuO}$-organic in terms of supramolecular interactions. ${ }^{20}$ The retrosynthetic analysis ${ }^{21} \mathrm{em}$ ployed in our studies is an integrated approach involving the concepts of Corey's synthon, Desiraju's supramolecular synthon ${ }^{22}$ and Wuest's tecton. ${ }^{23}$ By proposing a structure for the critical nucleus, we were able to generalize the architectures of copper-based hydroxide and chloride minerals as well as copper organic solids built from molecular building blocks to account for different lattice with the same composition, variation in metal ligand stoichiometry, degree of hydration and a link to chemical reactivity in the solution phase. ${ }^{12,20}$ This paper further explores the applicability of our pattern recognizing scheme to other phase diagrams like $\mathrm{CuSO}_{4}-\mathrm{H}_{2} \mathrm{O}-\mathrm{CuO}, \quad \mathrm{CuNO}_{3}-\mathrm{H}_{2} \mathrm{O}-\mathrm{CuO}$ and $\mathrm{CuCO}_{3}-\mathrm{H}_{2} \mathrm{O}-\mathrm{CuO}$ and derive insights for the crystallization of MOF-based solids from reactions that employ copper salts as reactants. The objective is to uncover the mechanisms underpinning intermolecular interactions in the self assembly of inorganic solids including minerals and identify the pattern of crystal packing to engineer the crystallization of new MOFs.

\section{Nucleation and crystallization of MOF solids from solution}

Desiraju refers crystallization as a supramolecular reaction. ${ }^{24}$ The crystallization process is considered to occur in two steps: nucleation and growth. Two recent articles have briefly discussed the issues related to nucleation and crystallization of solids from solution. ${ }^{25,26}$ In the context of crystal engineering, it means the stabilization of a particular arrangement of atoms and/or molecules from reacting species (solute as well as solvent molecules) at the supersaturation. In other words, the crystal structure of a solid represents a stable state where the intermolecular interactions are optimized to provide the most efficient packing - it may occur at the local minimum or global minimum on the energy landscape (figure 2). In the crystallization of molecular solids, intermolecular interactions influence their assembly and hence the crystal packing. ${ }^{27}$ Many people have made significant contributions to the crystal packing analysis of molecular solids: Kitaigorodsky's close packing principle, ${ }^{28}$ Etter's principles for hydrogen bonded crystals, ${ }^{29}$ Desiraju's concept of supramolecular synthons, ${ }^{22}$ short-contact analysis of crystals, statistical analysis of intermolecular contacts, etc. are a few notable ones. Pattern recognition by manual inspection or database analysis still remains a convenient way to analyse crystal structures. ${ }^{30}$ In contrast, crystal packing analysis of non-molecular solids (minerals, CP and MOF) is complex as both covalent and noncovalent interactions dominate.

A lot of theories have been proposed for the occurrence of nucleation ${ }^{25,26}$ though no interpretation of the same is available in terms of molecular recognition and aggregation of chemically reason- 
able molecules present in the solution. Nucleation is defined as the formation of dispersed nuclei from a homogeneous solution under supersaturation. Formation of a critical nucleus signals the separation of a solid phase from the solution. A critical nucleus thus represents the high energy intermediate, a liquidlike cluster or aggregate (supramolecular transition state) acting as a bridge between the solution and the solid. Classical nucleation theory considers the existence of a critical nucleus, corresponding to the maximum of energy versus radius curve. It is crucial to obtain information on its size and structure to understand early stages of crystallization. How does one link the crystal growth units in the solution to the molecular fragments observed in the solid state $?^{31}$ In the absence of a suitable mechanism for the nucleation highlighting molecular aggregation at supersaturation, it is difficult to interpret the results

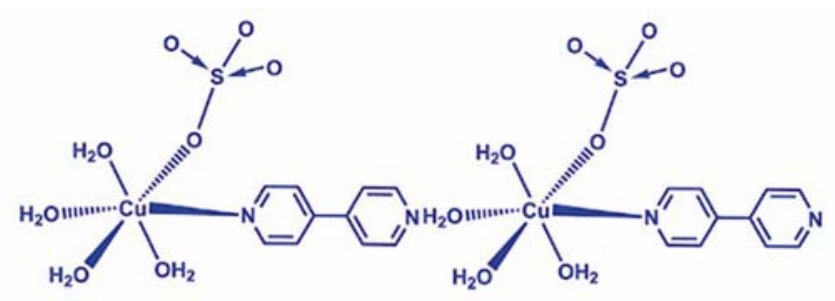

A

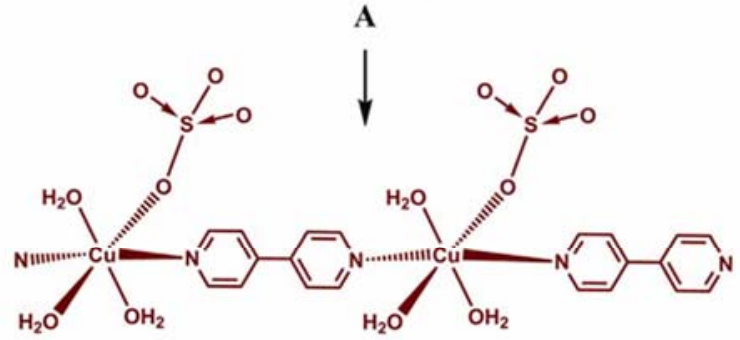

A

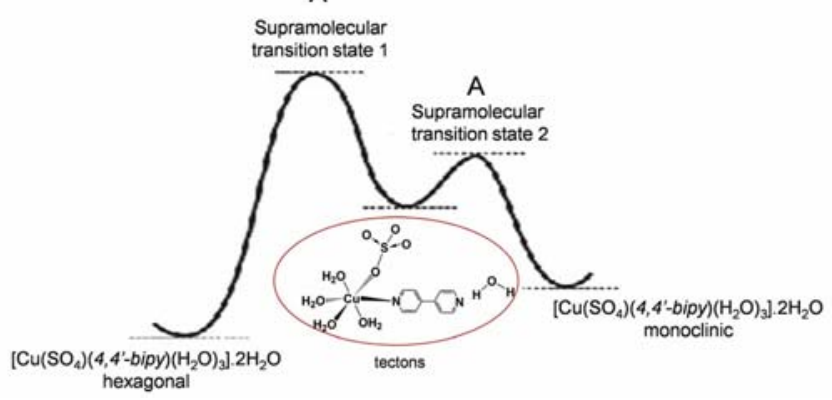

Figure 2. Energy profile diagram for the occurrence of copper organic polymorphs. The same set of tectons lead to two different critical nuclei as the supramolecular reaction pathway is altered by the reaction condition. Higher temperature favours the most stable hexagonal phase while milder condition results in the monoclinic symmetry. The structure differs in the way the water clustering occurs (refer figure 7). obtained from various crystallization studies. Use of analytical probes such as mass spectrometry, FTIR, NMR for solution characterization and time resolved in situ diffraction studies for solid state structure were invariably found to be inconclusive in characterizing the intermediates or the critical nuclei. ${ }^{32}$ Thus it becomes necessary to propose a structure for the critical nucleus. In figure 3 , we have provided the sequence of events that occur during the crystallization of a solid from a homogeneous solution: Dissolved molecules $\rightarrow$ complexes $\rightarrow$ dimers, oligomers or clusters $\rightarrow$ critical nucleus or supramolecular aggregate $\rightarrow$ the minute crystal $\rightarrow$ single crystal or

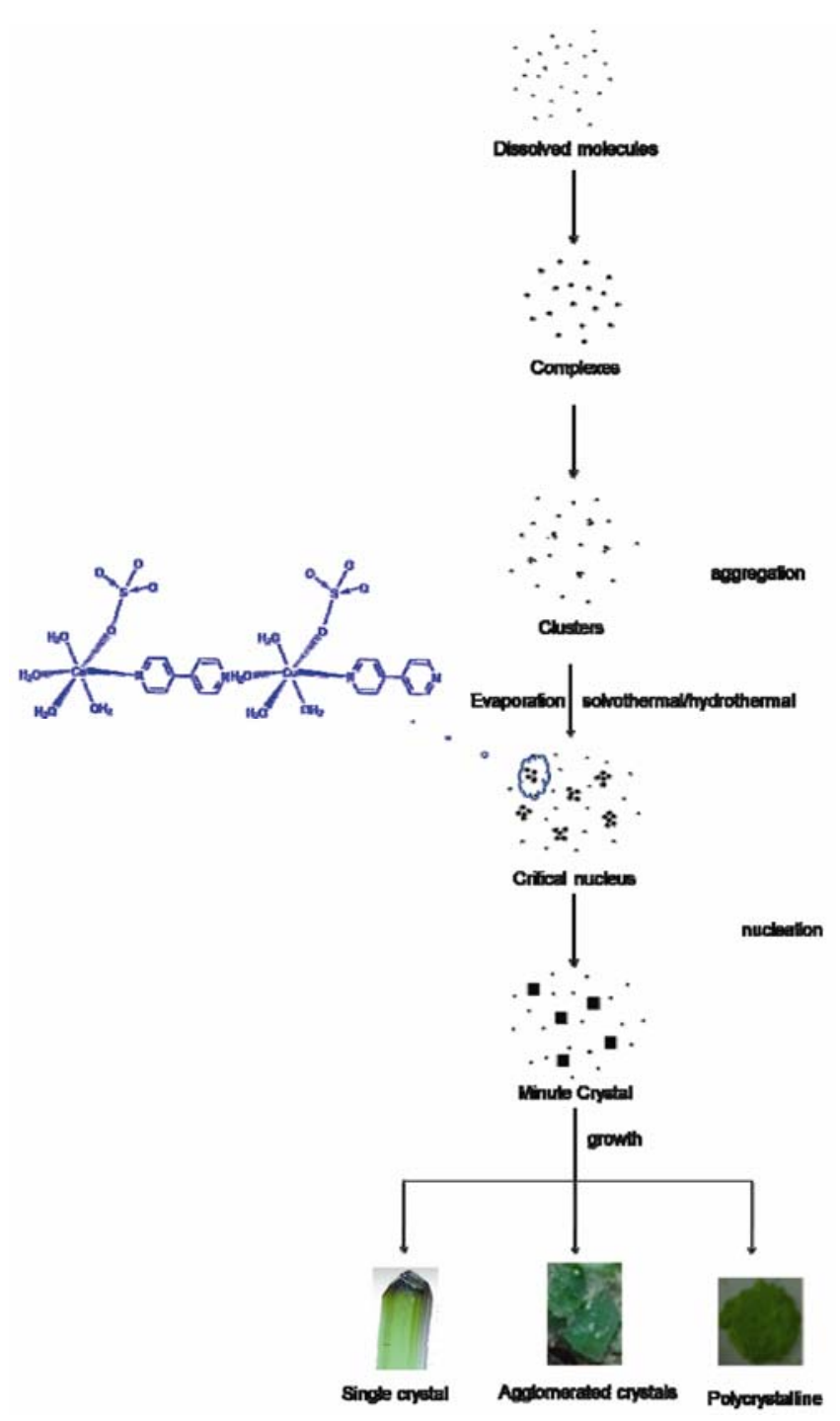

Figure 3. A schematic diagram representing the transformation of molecules in solution to a solid during crystallization reaction. Critical nucleus represents the supramolecular transition state. Nucleation refers to the stabilization of a minute crystal from a critical nucleus. 
polycrystalline. Supersaturation must occur, at least locally in nano or subnano volume to drive nucleation and crystal growth. For nucleation to occur, molecular aggregates (clusters) of the soluble species (henceforth referred to as tectons) must continually form and dissociate because of local concentration fluctuations. In a supersaturated solution outside the metastable region, the rate of formation of aggregates exceeds that of their dissociation. Once the nucleus attains a critical size (hence critical nucleus), a minute crystal with a particular lattice structure is stabilized (see figure 3). Now the growth of the minute crystal (morphology) will be dominated by a different kinetics. Here the rate of integration of aggregates into an existing lattice structure exceeds that rate of releasing the aggregating molecules from the surface, a process again driven by the local fluctuations. Proposing a structure for the critical nucleus in terms of supramolecular aggregation of tectons is advantageous on several fronts. The presence and geometry of tectons can be established by employing various analytical techniques. Self assembly is easy to recognize as one can visualize the operation of long range forces (covalent or non-covalent) in a particular system. Chemical reactions occurring at molecular level such as hydrolysis, nature of the metal complex including geometry and metal/ligand ratio, hydrophilic or hydrophobic cavities forming between aggregating groups and hence water clusters or solvent inclusion will all become meaningful.

\section{Drawing lessons from nature:}

\section{A retrosynthetic analysis of copper oxide-} based minerals

Minerals are crystalline inorganic compounds grown in natural environment mostly from aqueous medium. Minerals represent position of equilibrium or stability of a solid in a particular system. A retrosynthetic analysis of its structure can provide us insight into the nature of intermolecular interactions responsible for the condensation of the reacting species or tectons to result into a particular crystal packing. In our recent paper ${ }^{20}$ we rationalised the stability of phases known in the ternary system $\mathrm{CuCl}_{2}-\mathrm{H}_{2} \mathrm{O}-\mathrm{CuO}$ as well as the MOF crystallized from organic containing system. Dissolution of these solids leads to charged and neutral copper aqua, chloro and hydroxide species. At supersaturation, such species aggregate (critical nucleus) and con- dense to form the crystal - the bonds can be covalent, coordinate or non-covalent. In our analysis, a synthon refers to a $\mathrm{H}$-bonded aggregate (e.g. $-\mathrm{Cu}-$ $\left.\mathrm{X} \cdots \mathrm{OH}_{2}-\mathrm{Cu}\right)$ that may favour a covalent $-\mathrm{Cu}-\mathrm{X}-$ $\mathrm{Cu}-\left(\mathrm{X}=\mathrm{H}_{2} \mathrm{O}, \mathrm{Cl}, \mathrm{OH}\right)$ or non-covalent interaction during condensation. If such a synthon is associative favouring long range $-\mathrm{Cu}-\mathrm{X}-\mathrm{Cu}-\mathrm{X}-\mathrm{Cu}-$ interaction, then the synthons are termed as supramolecular synthons. The retrosynthetic analysis allowed us to propose a structure for the critical nucleus by considering a supramolecular reaction that involves aggregation of appropriate tectons directed by supramolecular synthons. Proposal of structures for critical nuclei in the system $\mathrm{CuCl}_{2}-\mathrm{H}_{2} \mathrm{O}-\mathrm{CuO}$ postulates the condensation pathways for the copper tectons. ${ }^{20}$ Such an analysis readily allows one to recognize the long range interactions (covalent as well as non-covalent) favouring a particular lattice structure and hence the crystallization of a hydrate, polymorph or pseudopolymorph of a mineral.

Can we extend this analysis to minerals known in other systems such as $\mathrm{CuSO}_{4}-\mathrm{H}_{2} \mathrm{O}-\mathrm{CuO}, \mathrm{CuCO}_{3}-$ $\mathrm{H}_{2} \mathrm{O}-\mathrm{CuO}$ and $\mathrm{CuNO}_{3}-\mathrm{H}_{2} \mathrm{O}-\mathrm{CuO}$ ? Table 1 lists copper sulfate (carbonate and nitrate) based minerals crystallized from aqueous medium; a few are hydrated, some occur as polymorphs and pseudopolymorphs. As long as $\mathrm{pH}$ is below $\mathrm{pKa}$ of the reaction, ${ }^{32}\left[\mathrm{Cu}\left(\mathrm{H}_{2} \mathrm{O}\right)_{6}\right]^{2+} \rightarrow\left[\mathrm{Cu}\left(\mathrm{H}_{2} \mathrm{O}\right)_{5}(\mathrm{OH})\right]^{+}+\mathrm{H}_{2} \mathrm{O}$, the tectons will be $\left[\mathrm{Cu}\left(\mathrm{H}_{2} \mathrm{O}\right)_{6}\right]^{2+}$ and $\mathrm{SO}_{4}^{2-}$ in the molar ratio $1: 1$ or $\left[\mathrm{Cu}\left(\mathrm{H}_{2} \mathrm{O}\right)_{5} \mathrm{SO}_{4}\right]^{0}$ (overall charge of the aggregating species at the critical nucleus must be neutral). Figure 4 shows how supramolecular condensation between zwitter-ionic copper sulfate tectons take place in four different ways leading to the crystallization of the pseudopolymorphs, a textbook example. The phases represent a beautiful crystal engineering practiced by nature to account for the $1: 1$ stoichiometry of copper sulfate and the variation in the degree of hydration. A similar analysis is applicable for all phase diagrams involving salt hydrates. ${ }^{33}$ The force of interaction (varying temperature at $1 \mathrm{~atm}$ or varying water pressure or humidity at $300 \mathrm{~K}$ ) between self assembling molecules is evident by examining the different pathways for supramolecular condensation. Transformation of molecules into crystal is manifested in the way the sulfate ligand bridges with copper ions-complete covalent bonding in anhydrous $\mathrm{CuSO}_{4}$ to coexistence of covalent and non-covalent interactions in the hydrated phases. The role of bridging ligands like chloride, hydroxide, sulfate, carbonate or nitrate will all become obvious if we carefully analyse crys- 
Table 1. Various tectons involved in the formation of copper salt-based minerals crystallized from aqueous medium.

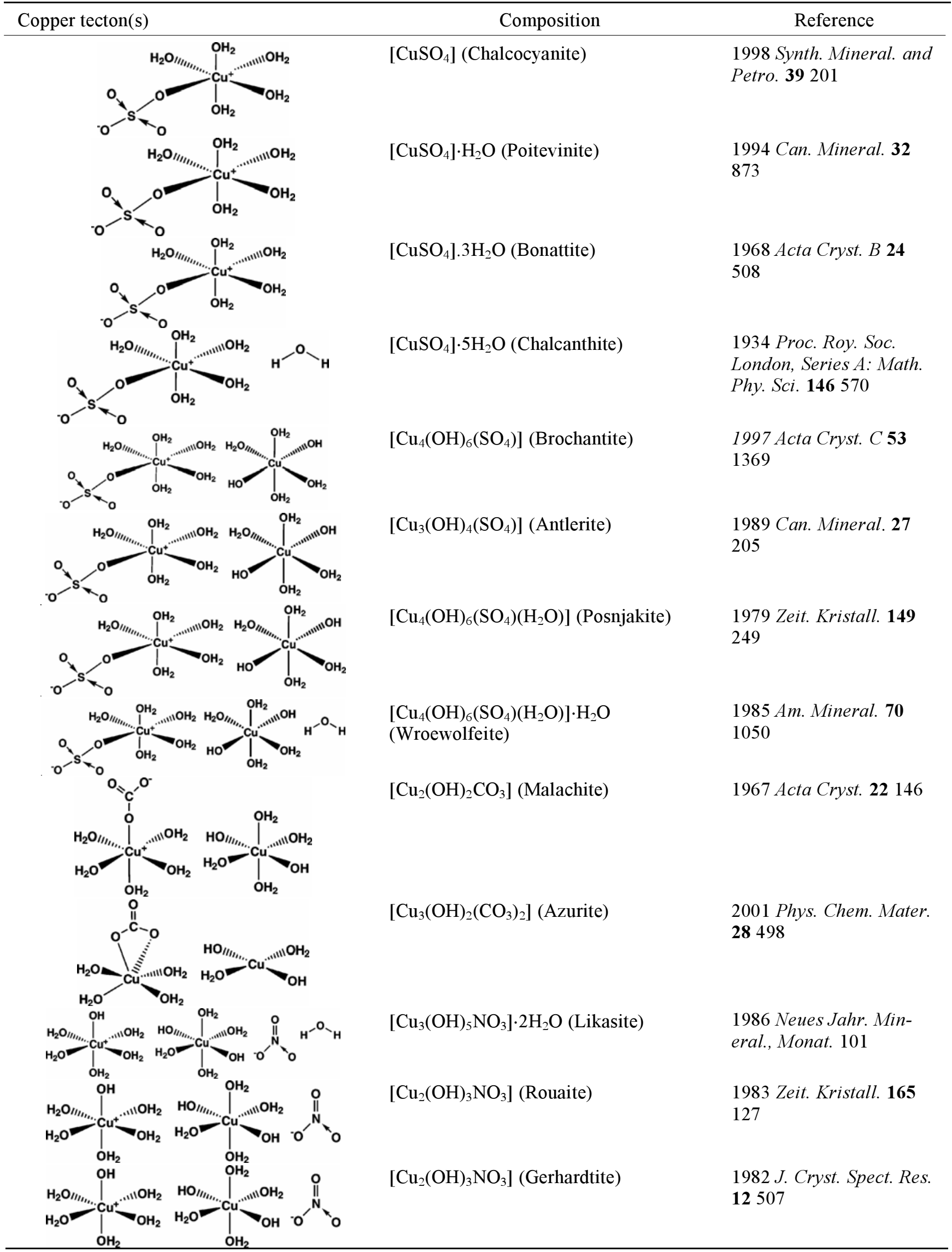




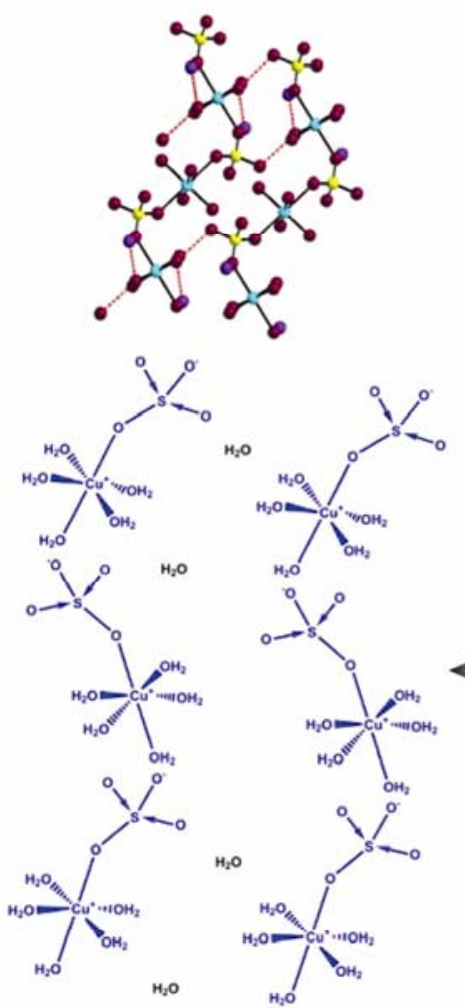

[CuSO $4.5 \mathrm{H}_{2} \mathrm{O}$ ] Chalcanthite

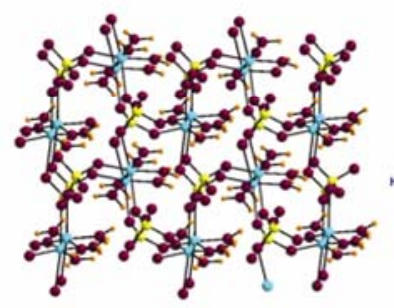

$\left[\mathrm{CuSO}_{4}\right]$ Chalcocyanite
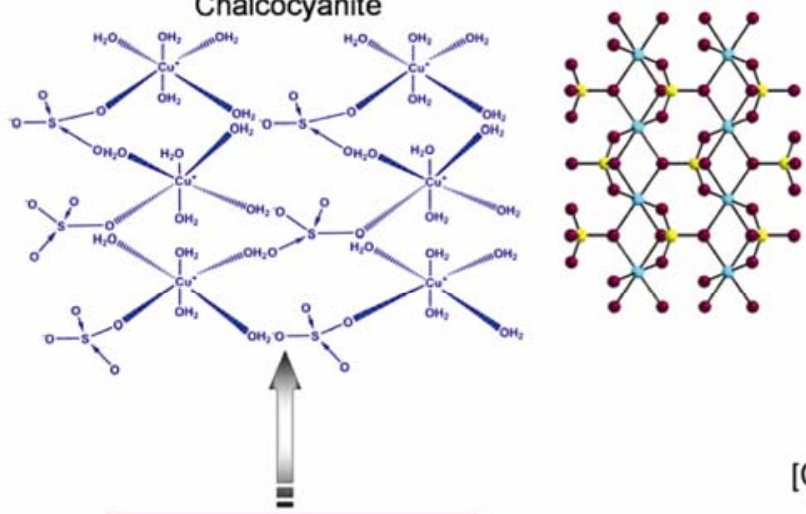

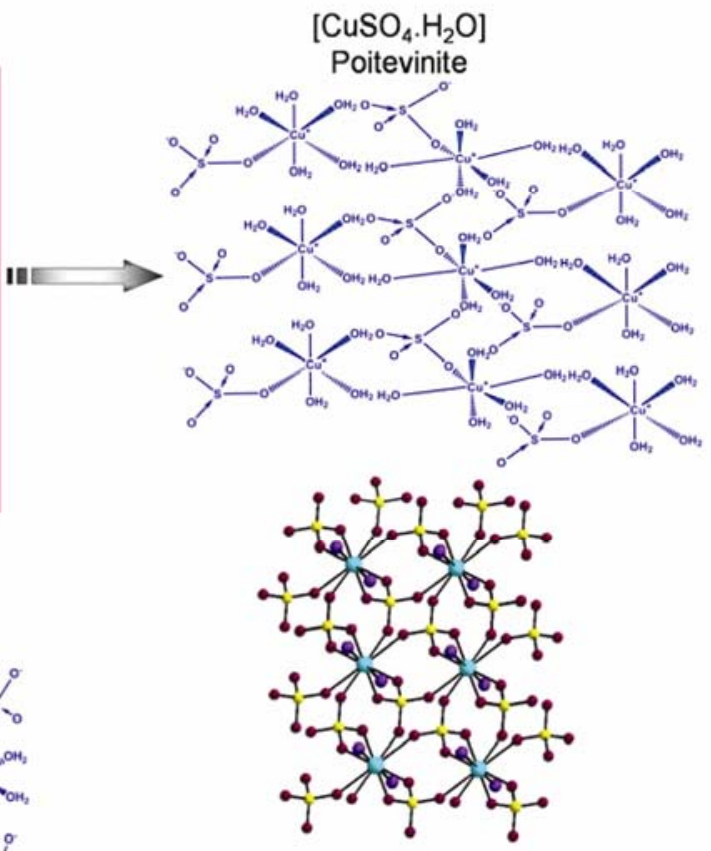

Figure 4. Crystal engineering of soluble zwitter ion, $\left[\mathrm{Cu}\left(\mathrm{H}_{2} \mathrm{O}\right)_{5} \mathrm{SO}_{4}\right]^{0}$ (tecton) into different copper sulphate pseudopolymorphs. Notice how the external variables (temperature at latm or water vapour pressure at $25^{\circ} \mathrm{C}$ ) induce different supramolecular aggregation and hence alternate pathways for condensation.

tallization in terms of tectons as building blocks. In $\mathrm{CuSO}_{4} \cdot 5 \mathrm{H}_{2} \mathrm{O}$, effective packing requires an additional water molecule and hence water mediation. ${ }^{34}$ Recently Zhang et $\mathrm{al}^{35}{ }^{35}$ have grown an unusual zeolitic copper sulfate, $\mathrm{Cu}_{12}\left(\mathrm{SO}_{4}\right)_{12} \cdot 4 \mathrm{H}_{2} \mathrm{O}$ or $\mathrm{CuSO}_{4}$. $1 / 3 \mathrm{H}_{2} \mathrm{O}$ from a complex soup; such examples of a metastable phase is not uncommon in solid state chemistry. If $\mathrm{pH}$ is slightly altered to disrupt the above equilibrium (addition of a mineral or organic base), the cupric hydrate will undergo hydrolysis forming $\left[\mathrm{Cu}\left(\mathrm{H}_{2} \mathrm{O}\right)_{5}(\mathrm{OH})\right]^{+}$and $\left[\mathrm{Cu}\left(\mathrm{H}_{2} \mathrm{O}\right)_{4}(\mathrm{OH})_{2}\right]^{0}$. However, the zwitter ion, $\left[\mathrm{Cu}\left(\mathrm{H}_{2} \mathrm{O}\right)_{5} \mathrm{SO}_{4}\right]^{0}$ can not hydrolyse. These species can now induce a different supramolecular aggregation at the supersaturation with varying stoichiometries and hence the occurrence of pseudopolymorphs of anhydrous and 


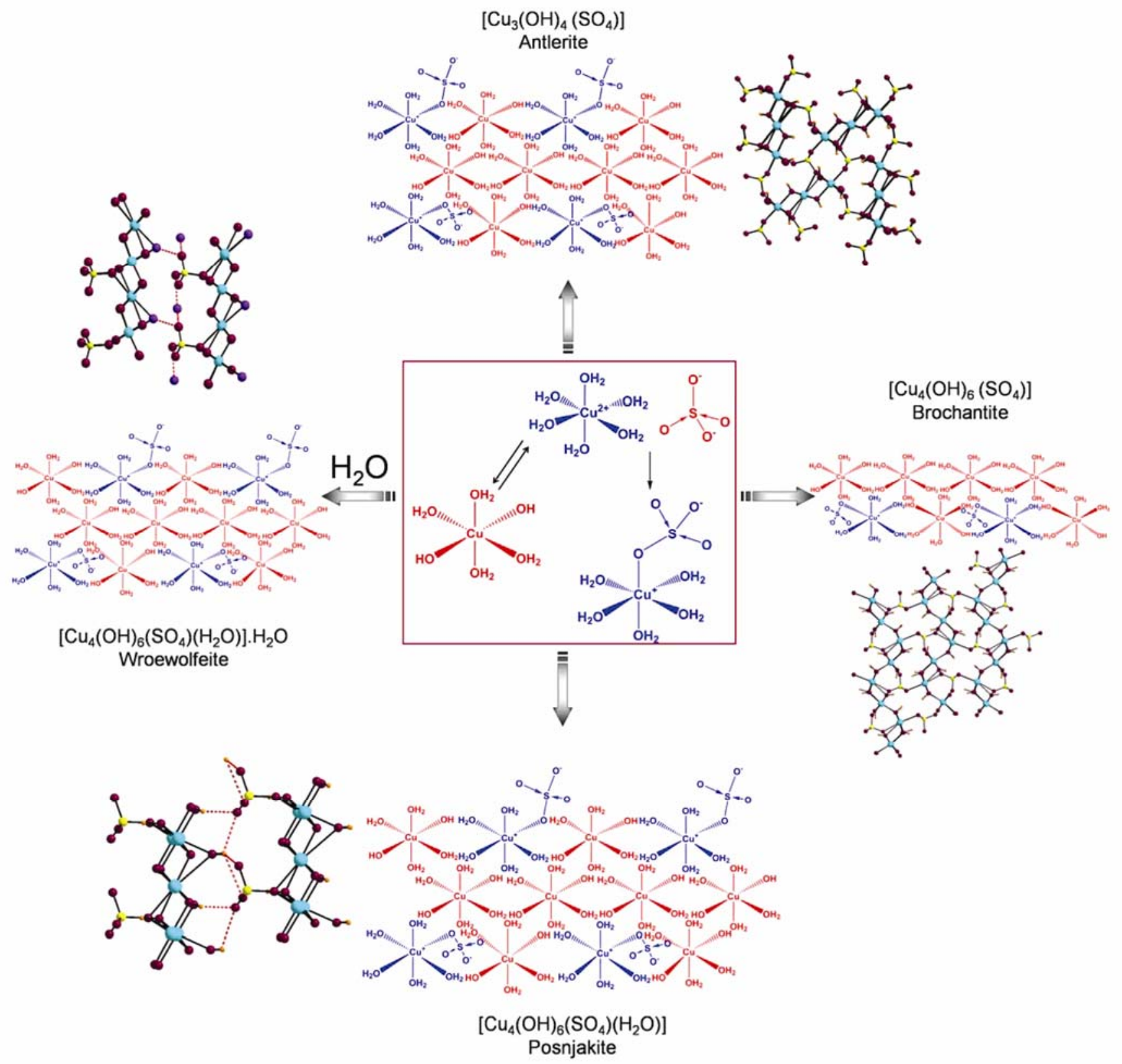

Figure 5. Local $\mathrm{pH}$ changes lead to the hydrolysis of the cupric hydrate and hence two different species $\left[\mathrm{Cu}\left(\mathrm{H}_{2} \mathrm{O}\right)_{4}(\mathrm{OH})_{2}\right]^{0}$ and the zwitter ion, $\left[\mathrm{Cu}\left(\mathrm{H}_{2} \mathrm{O}\right)_{5} \mathrm{SO}_{4}\right]^{0}$ in the supramolecular reaction; the latter one cannot hydrolyze. Supramolecular aggregation of the two species with varying stoichiometries leading to the different pseudopolymorphs of anhydrous and hydrated copper hydroxy sulfates.

hydrated copper hydroxy sulfates (figure 5 and table 1).

In a similar way, the crystallization of polymorphs in the system $\mathrm{CuNO}_{3}-\mathrm{H}_{2} \mathrm{O}-\mathrm{CuO}$, and the two pseudopolymorphs (azurite and malachite) in the system $\mathrm{CuCO}_{3}-\mathrm{H}_{2} \mathrm{O}-\mathrm{CuO}$ can be rationalized (table 1) through the process of supramolecular condensation. The mechanism for the slow conversion of malachite to azurite on exposure to moisturised $\mathrm{CO}_{2}$ is a puzzle still to be solved. In all probability, the nucleation occurs through a dissolution followed by condensation and the driving force is the change in composition at the nucleating site. Our mechanistic approach can also explain why single crystals of $\mathrm{CuCO}_{3}$ are difficult to achieve from aqueous solution; higher $\mathrm{pH}$ is required for the formation of carbonate tecton, 
Table 2. Retrosynthetic analysis of copper sulphate/carbonate-based metal organic solids.

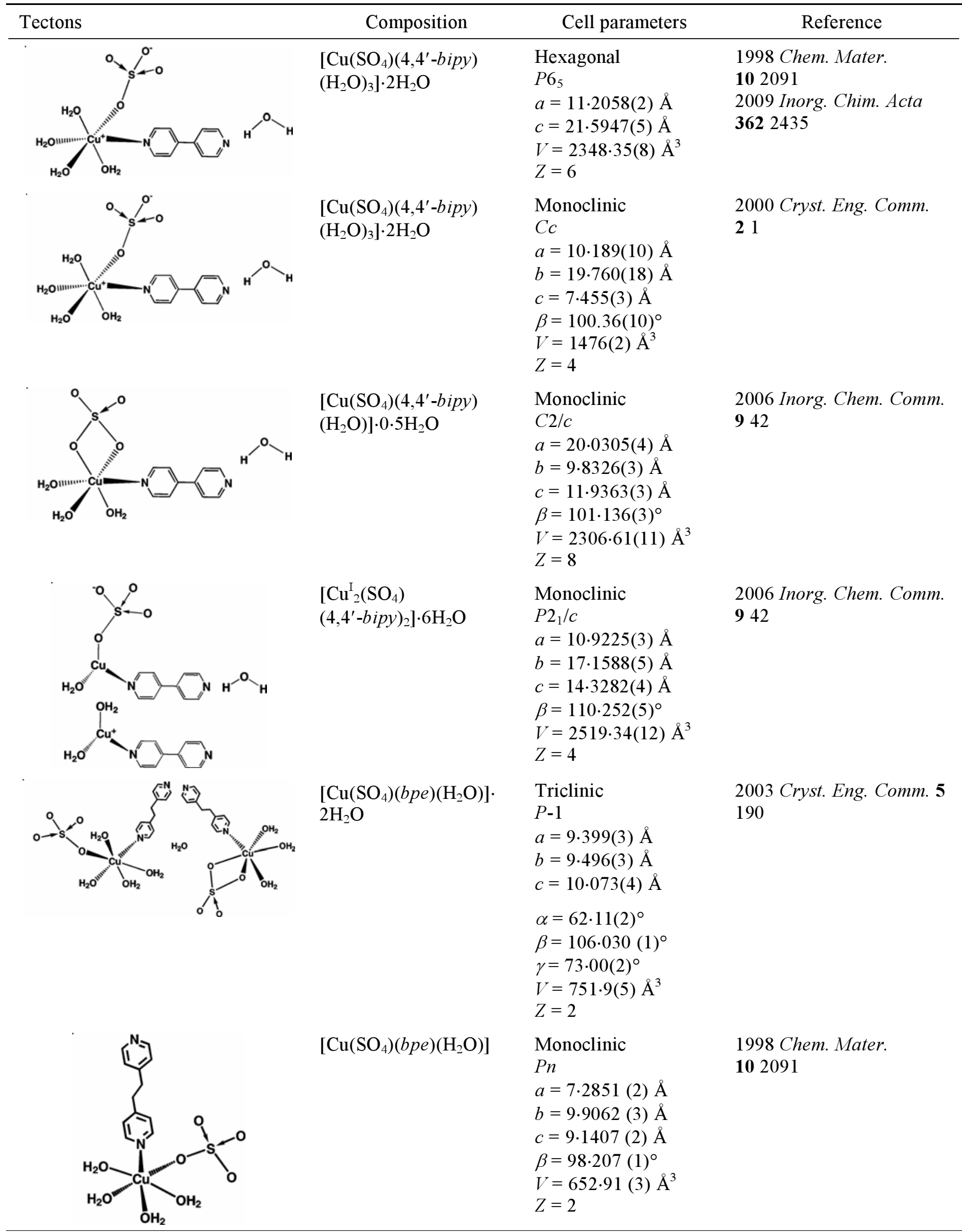


Table 2. (Contd...)

\begin{tabular}{|c|c|c|c|}
\hline Tectons & Composition & Cell parameters & Reference \\
\hline & $\begin{array}{l}{\left[\left\{\mathrm{Cu}(\text { bpe })_{2}\right\}\{\mathrm{Cu}(\text { bpe })\right.} \\
\left.\left.\left(\mathrm{H}_{2} \mathrm{O}\right)_{2}\left(\mathrm{SO}_{4}\right)_{2}\right\}\right] \cdot 2 \mathrm{H}_{2} \mathrm{O}\end{array}$ & $\begin{array}{l}\text { Monoclinic } \\
P n \\
a=22 \cdot 9863 \text { (1) } \AA \\
b=13 \cdot 4707 \text { (1) } \AA \\
c=13 \cdot 4902(1) \AA \\
\beta=106.030(1)^{\circ} \\
V=4014 \cdot 71(5) \AA^{3} \\
Z=8\end{array}$ & $\begin{array}{l}1998 \text { Chem. Mater. } \\
102091\end{array}$ \\
\hline & {$\left[\mathrm{Cu}\left(\mathrm{CO}_{3}\right)(d p a)\right] \cdot 3 \mathrm{H}_{2} \mathrm{O}$} & $\begin{array}{l}\text { Monoclinic } \\
P 2_{1} / c \\
a=11 \cdot 209(1) \AA \\
b=7 \cdot 107(1) \AA \\
c=17 \cdot 339(1) \AA \\
\beta=100 \cdot 891(1)^{\circ} \\
V=1356 \cdot 37(10) \AA^{3} \\
Z=4\end{array}$ & $\begin{array}{l}2001 \text { Cryst. Eng. } \\
\text { Comm. } \mathbf{3 4} 1\end{array}$ \\
\hline
\end{tabular}

$\left(4,4^{\prime}\right.$-bipy $=4,4^{\prime}$-bipyridyl, bpe $=$ bis(4-pyridyl)ethane, $d p a=$ dipyridylamine $)$.

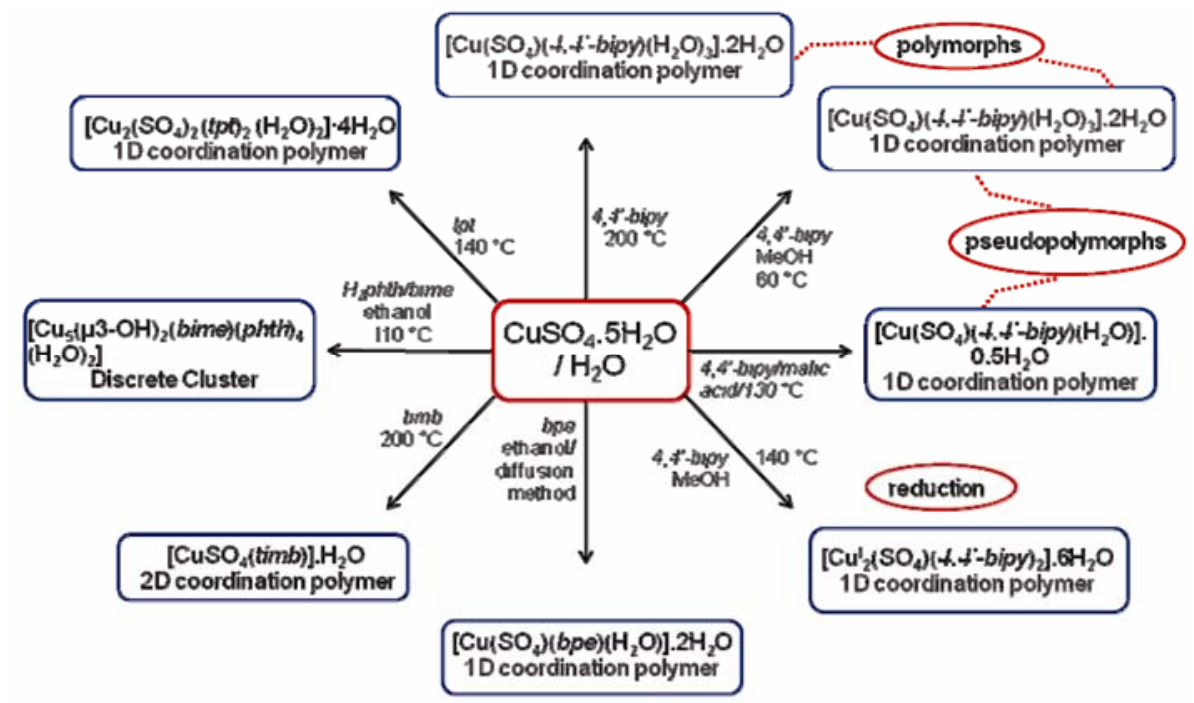

Figure 6. Crystallization of a few selected copper-organic solids from the system $\mathrm{CuSO}_{4}-\mathrm{H}_{2} \mathrm{O}-$ org. Solid state architectures, compositional variation and water aggregation can be accounted for on molecular level by considering the supramolecular aggregation of appropriate tectons (refer table 2).

$\left[\mathrm{CuCO}_{3}\left(\mathrm{H}_{2} \mathrm{O}\right)_{5}\right]^{0}$ while the rate of formation of the hydroxide tecton $\left[\mathrm{Cu}\left(\mathrm{H}_{2} \mathrm{O}\right)_{4}(\mathrm{OH})_{2}\right]^{0}$ will be very high at this $\mathrm{pH}$.

\section{Chemical insights into the crystallization of copper based metal organic solid}

Crystallization of a metal organic solid can be considered as a modification of the above systems: $\mathrm{CuX}_{2-}$
$\mathrm{H}_{2} \mathrm{O}$-organic $\left(\mathrm{X}=\mathrm{Cl}, \mathrm{OH}\right.$ or $\left.\mathrm{NO}_{3}\right)$ or $\mathrm{CuX}-\mathrm{H}_{2} \mathrm{O}-$ organic $\left(\mathrm{X}=\mathrm{SO}_{4}\right.$ or $\left.\mathrm{CO}_{3}\right)$. Here the solution (aqueous or non-aqueous) is made by dissolving a copper salt along with a chelating organic molecule. Three possibilities can occur in the solution: (i) copper can form a complex or a chelate, (ii) soluble cupric species or its complex can condense into a stable cluster and (iii) copper(II) may undergo reduction by organic group to form $\mathrm{Cu}(\mathrm{I})$ species. At super- 


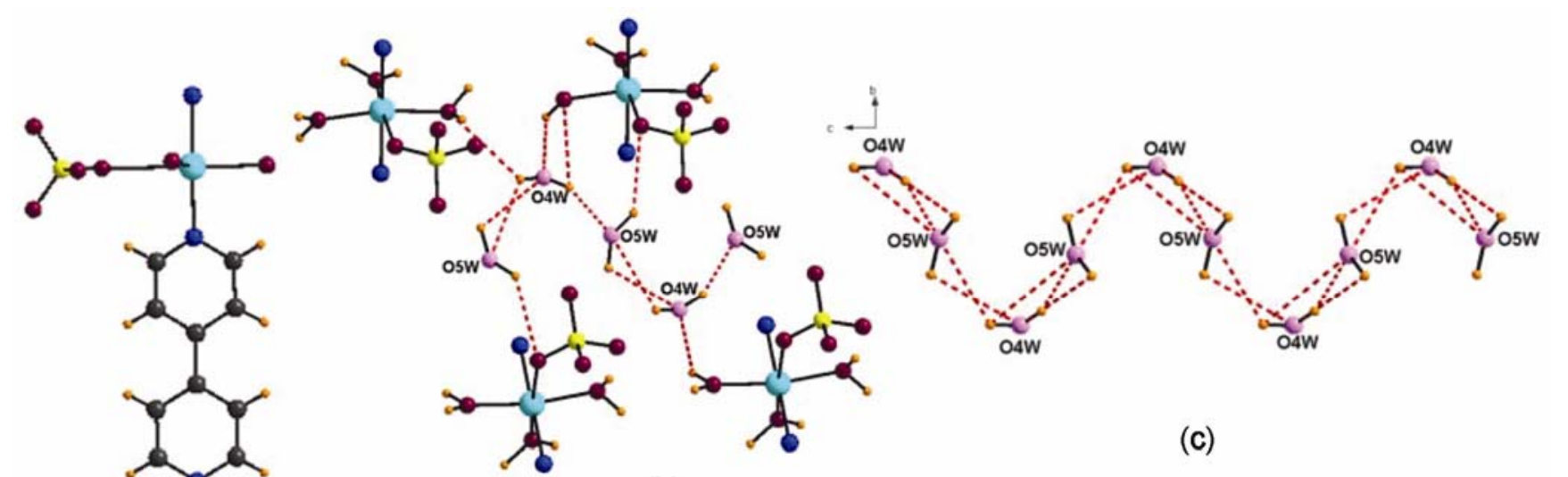

(b)

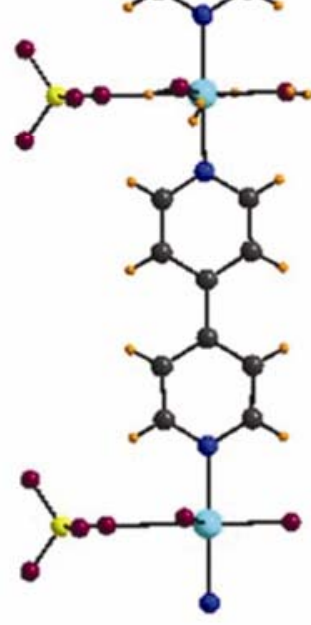

(a)

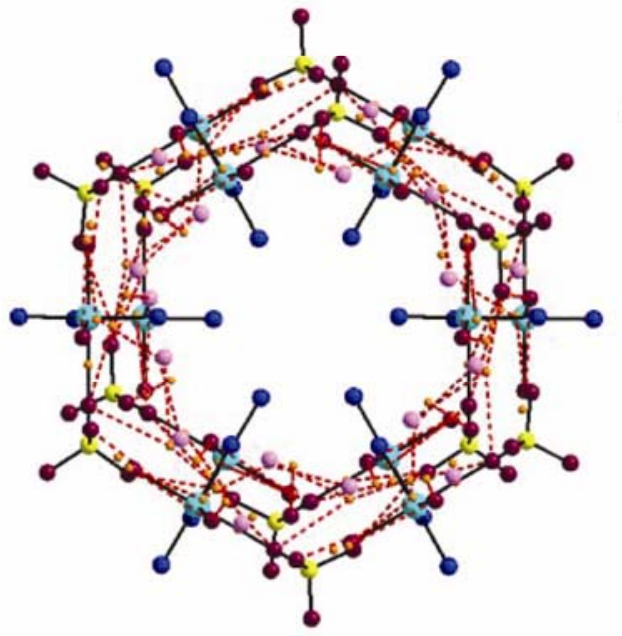

(d)

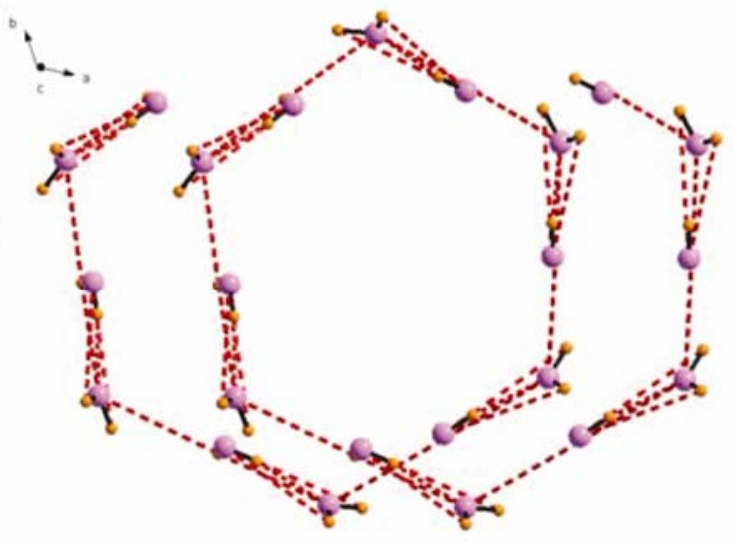

(e)

Figure 7. Crystallization of both hexagonal and monoclinic phases of the composition $\left[\mathrm{Cu}\left(\mathrm{SO}_{4}\right)\left(4,4^{\prime}-\right.\right.$ bipy) $\left.\left(\mathrm{H}_{2} \mathrm{O}\right)_{3}\right] \cdot 2 \mathrm{H}_{2} \mathrm{O}$ is a compromise of dominating covalent interactions forming $1 \mathrm{D}$ coordination polymers (a) and extended water interactions between mediating water molecules. In both phases the water chains interact with sulfate and coordinated water molecules. The higher temperature probably forces a stronger nonbonding interaction that results in a helical water chains for the hexagonal phase. (Carbon atoms are removed for clarity in (b) and (d)).

saturation, any one or more of these soluble species can aggregate through supramolecular interactions and eventually result in a particular crystal. To make a meaningful structure-synthesis correlation, it is essential to examine the crystal packing of a structure through condensation of appropriate tectons. Recently we reported how different condensation pathways lead to the crystallization of copper organic solids based on copper chloride and hydroxide. ${ }^{12,20}$ In this paper, we have examined the system $\mathrm{CuSO}_{4}-\mathrm{H}_{2} \mathrm{O}$-org (table 2). Crystallization of metal organic phases from the system $\mathrm{CuSO}_{4}-\mathrm{H}_{2} \mathrm{O}-4,4$ 'bipy is an interesting case for examination. Four phases have been isolated of which one is $\mathrm{Cu}^{\mathrm{I}}$ based (figure 6). The two polymorphic hydrates (hexagonal and monoclinic) observed for the composition
$\left[\mathrm{CuSO}_{4}\left(4,4^{\prime}-\right.\right.$ bipy $\left.)\left(\mathrm{H}_{2} \mathrm{O}\right)_{3}\right] \cdot 2 \mathrm{H}_{2} \mathrm{O}$ is an elegant example of crystal engineering demonstrated between same set of molecules at two different condition. In both solids, the dominating assembly is the formation of 1D linear coordination polymers. However, the difference in space symmetry is dictated the way the two mediating water molecules interact with the chains (figure 7). Hydrothermal reaction at higher temperature forces stronger non-bonding interactions and hence a hexagonal symmetry; a helical symmetry $\left(6_{1}\right)$ connects copper chains as well as the extended mediating water molecules. A milder condition, however results in a weaker interaction and hence lower monoclinic symmetry (figure 7). In the other monoclinic phase, $\left[\mathrm{Cu}\left(\mathrm{SO}_{4}\right)\left(4,4^{\prime}-\right.\right.$ bipy) $\left.\left(\mathrm{H}_{2} \mathrm{O}\right)\right] \cdot 0 \cdot 5 \mathrm{H}_{2} \mathrm{O}$, the tecton has a bidentate 


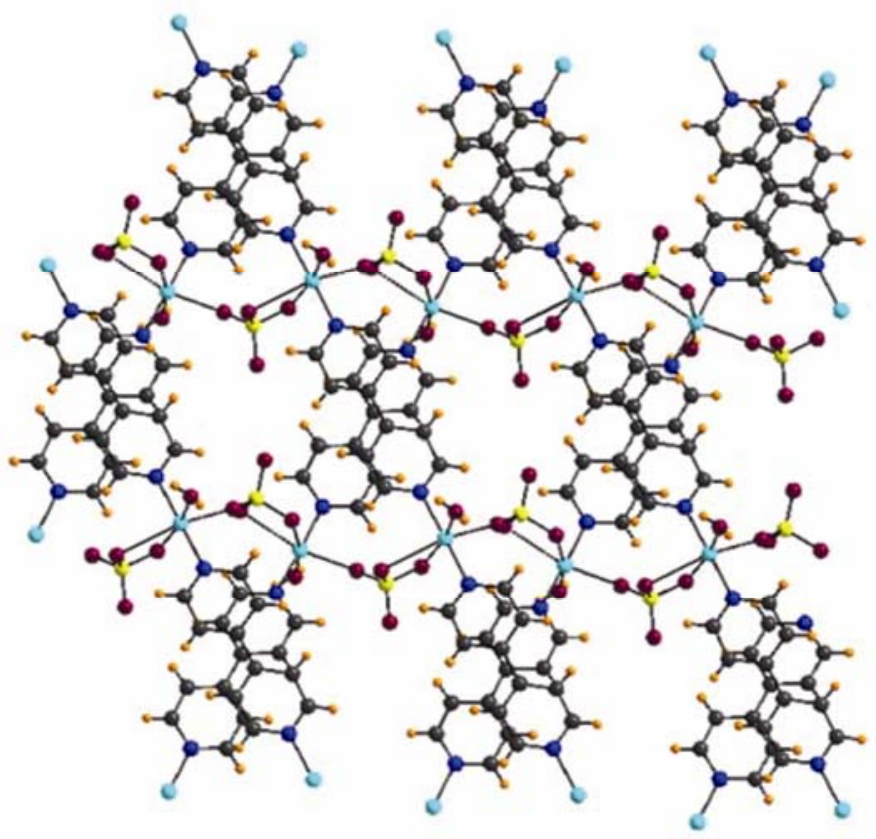

(a)

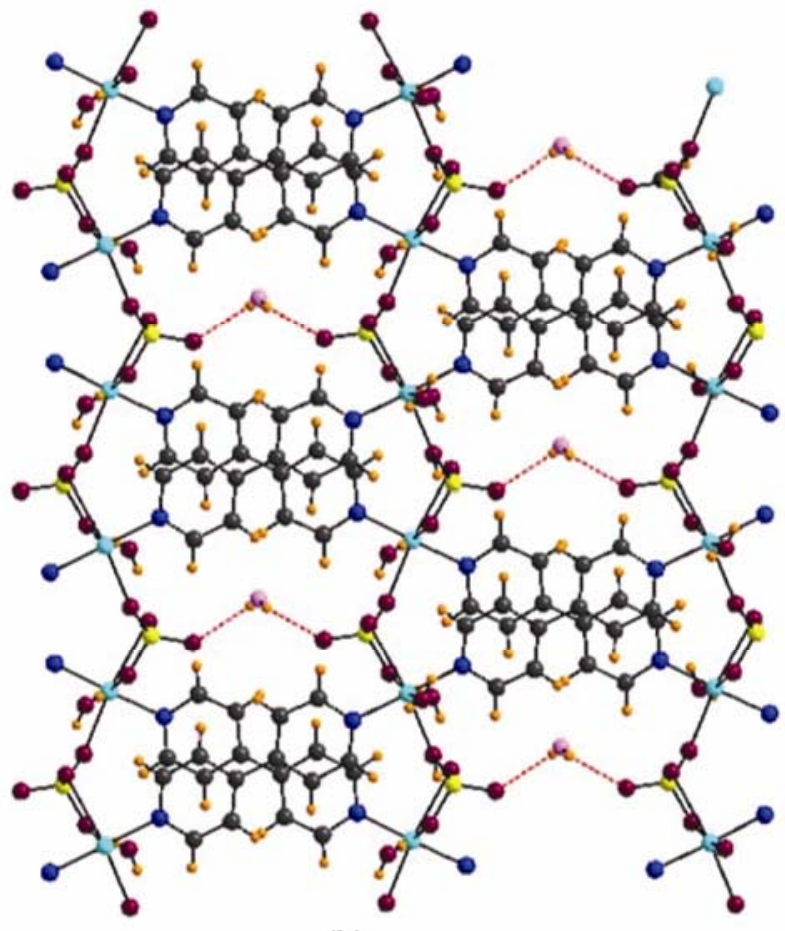

(b)

Figure 8. Crystallization of $\left[\mathrm{Cu}\left(\mathrm{SO}_{4}\right)\left(4,4^{\prime}-\right.\right.$ bipy $\left.)\left(\mathrm{H}_{2} \mathrm{O}\right)\right] \cdot 0 \cdot 5 \mathrm{H}_{2} \mathrm{O}$ is due to the formation of the tecton, $\left[\mathrm{Cu}\left(\mathrm{SO}_{4}\right)\left(4,4^{\prime}-\right.\right.$ bipy) $\left.\left(\mathrm{H}_{2} \mathrm{O}\right)_{4}\right]^{0}$ wherein the sulphate is a bidentating ligand. $\mathrm{Cu}$ coordination is fulfilled by two nitrogens of $4,4^{\prime}-$ bipy, three oxygens of sulfate groups and one water molecule. (a) $2 \mathrm{D}$ sheet formed by $\left\{\mathrm{Cu}\left(\mathrm{SO}_{4}\right)\left(4,4^{\prime}-\right.\right.$ bipy $\left.)\left(\mathrm{H}_{2} \mathrm{O}\right)\right\}$ chains linked through sulfate groups. (b) Water mediation stabilizing the 3D structure.

sulfate group; the $1 \mathrm{D}$ chain still dominates the packing but the sulfate groups condenses with two water molecules of the copper coordination and hence the composition with lesser number of water around copper. The structure also shows the presence of one mediating water molecule that connects a pair of chains (figure 8).

Unlike chloride and sulfate, carbonate based metal organic solids are quite rare. There are only two examples known. $\left[\mathrm{CuCO}_{3}(d p a)\right](d p a=$ dipyridylamine) wherein the copper (dpa) complex is extended into chains through bidentating and monodentating carbonate groups (table 2). A similar structure also exist for the solid $\mathrm{CuCO}_{3}\left(\mathrm{NH}_{3}\right)_{2}{ }^{36} \mathrm{~A}$ discrete complex based solid, $\left[\mathrm{Cu}_{4}\left(\mathrm{CO}_{3}\right)_{2}(\text { tppnol })_{2}\right]$. $\left(\mathrm{ClO}_{4}\right)_{2} \cdot 6 \mathrm{H}_{2} \mathrm{O} \quad$ (Htppnol $=N, N, N^{\prime}$-tris-(2-pyridylmethyl)-1,3-diaminopropan-2-ol) is also known. ${ }^{37}$ By appropriate choice of organic groups, it is possible to prepare new metal organic solids of the composition $\mathrm{CuCO}_{3}(\mathrm{org})$. Probing chemistry issues concerning the formation of metal organic carbonates at the molecular level may have long term implications to the conservationists for preserving old paint- ings containing pigments such as auzrite as well for fixing carbon dioxide in air through new MOF.

Copper acetate is another salt that is commonly employed as copper source in the synthesis of copperbased MOF. Unlike carbonate or acetate, aromatic di- or tri-carboxylates are more versatile to provide multidimensional covalent linkages; the aromatic groups can further influence crystal packing through specific $\pi \cdots \pi$ and $\mathrm{CH} \cdots \pi$ interactions. Table 3 lists some selected examples with a brief account of experimental condition employed for its crystallization. Solid state structures of copper-based carboxylates $^{38}$ are unique among the first row transition metals as the tectons with variable geometry dictates varying reactivity and self-assembling properties. A quick examination of the table suggests that the choice of the reactants and solvent assists to overcome the solubility of copper and organic in a medium. However, rationalization of the composition and solvent inclusion in the most celebrated examples like HKUST1 and MOF-505 (table 3) requires a detailed structure-synthesis correlation along the lines discussed above. 
Table 3. Retrosynthetic analysis of copper-arylcarboxylate based MOFs and CPs.

\begin{tabular}{|c|c|c|c|}
\hline Tectons & Composition & Experimental Conditions & Reference \\
\hline $\begin{array}{l}\mathrm{H}_{2} \mathrm{O} \\
\mathrm{HO}\end{array}$ & {$\left[\mathrm{Cu}(b d c)\left(\mathrm{H}_{2} \mathrm{O}\right)\right] \cdot \mathrm{H}_{2} \mathrm{O}$} & $\begin{array}{l}\mathrm{Cu}(\mathrm{OAc})_{2} \cdot \mathrm{H}_{2} \mathrm{O} / b d c l \\
\text { imidazole } / 2: 2: 1 \text { in } \mathrm{H}_{2} \mathrm{O} \\
\text { and } n \text {-propyl alcohol } \\
\text { at } 160^{\circ} \mathrm{C} \text { for } 5 \text { days }\end{array}$ & $\begin{array}{l}2003 \text { Inorg. } \\
\text { Chem. Commun. } \\
61249\end{array}$ \\
\hline & $\begin{array}{l}{\left[\mathrm{Cu}_{3}(t m a)_{2}\left(\mathrm{H}_{2} \mathrm{O}\right)_{3}\right]} \\
\text { HKUST1 }\end{array}$ & $\begin{array}{l}\mathrm{CuNO}_{3} \cdot 3 \mathrm{H}_{2} \mathrm{O} / \\
\mathrm{H}_{3} \mathrm{TMA} / 2: 1 \text { in } 50: 50 \\
\mathrm{H}_{2} \mathrm{O}: \mathrm{EtOH} \text { at } 180^{\circ} \mathrm{C} \\
\text { for } 12 \mathrm{~h}\end{array}$ & $\begin{array}{l}1999 \text { Science } \\
\mathbf{2 8 3} 1148\end{array}$ \\
\hline & $\begin{array}{l}{\left[\mathrm{Cu}_{2}(\mathrm{OH})(t m a)\left(\mathrm{H}_{2} \mathrm{O}\right)\right] \cdot} \\
2 \mathrm{H}_{2} \mathrm{O}\end{array}$ & $\begin{array}{l}\mathrm{CuNO}_{3} \cdot 3 \mathrm{H}_{2} \mathrm{O} / \\
\mathrm{H}_{3} \mathrm{TMA} / 1: 3 \mathrm{in} \mathrm{H}_{2} \mathrm{O} \\
\text { at } 120^{\circ} \mathrm{C} \text { for } 24 \mathrm{~h}\end{array}$ & $\begin{array}{l}2003 \text { Chem. Lett. } \\
32590\end{array}$ \\
\hline & {$\left[\mathrm{Cu}(t m a)\left(\mathrm{H}_{2} \mathrm{O}\right)_{3}\right]$} & $\begin{array}{l}\text { Diffusion of an aqueous } \\
\text { solution of } \mathrm{Cu}\left(\mathrm{ClO}_{4}\right)_{2} \text { into } \\
\text { tma in ethanol }\end{array}$ & $\begin{array}{l}1988 \text { Acta Cryst. } \\
\text { C44992 }\end{array}$ \\
\hline $\mathrm{HO}$ & {$\left[\mathrm{Cu}_{2}(\mathrm{btc})_{2}\left(\mathrm{H}_{2} \mathrm{O}\right)_{3}\right] \cdot 2 \mathrm{H}_{2} \mathrm{O}$} & $\begin{array}{l}\mathrm{Cu}\left(\mathrm{NO}_{3}\right)_{2} \cdot 3 \mathrm{H}_{2} \mathrm{O} / \text { btc } \\
\text { anhydride } / 1: 1 \text { in } 10 \mathrm{ml} \\
\mathrm{H}_{2} \mathrm{O} \text {. pH was adjusted to } \\
4 \cdot 5 \text { by triethylamine. The } \\
\text { reaction was heated at } \\
160^{\circ} \mathrm{C} \text { for } 5 \text { days }\end{array}$ & $\begin{array}{l}2004 \text { Inorg. } \\
\text { Chem. Commun. } \\
7788\end{array}$ \\
\hline & {$\left[\mathrm{Cu}_{3}(\mathrm{OH})_{2}(\right.$ btec $\left.)\right]$} & $\begin{array}{l}\mathrm{CuCl}_{2} \cdot 2 \mathrm{H}_{2} \mathrm{O} / \mathrm{H}_{4} \text { btec/imH/ } \\
\mathrm{NaOH} / 1: 1: 1: 2 \text { in } 1: 1 \\
(v / v) \mathrm{MeOH}-\mathrm{H}_{2} \mathrm{O} \text { at } 140^{\circ} \mathrm{C} \\
\text { for } 2 \text { days }\end{array}$ & $\begin{array}{l}2002 \text { Inorg. } \\
\text { Chem. } 416161\end{array}$ \\
\hline & {$\left[\mathrm{Cu}_{2}(\right.$ btec $\left.)\left(\mathrm{H}_{2} \mathrm{O}\right)_{4}\right] \cdot 2 \mathrm{H}_{2} \mathrm{O}$} & $\begin{array}{l}\mathrm{CuCl}_{2} \cdot 2 \mathrm{H}_{2} \mathrm{O} / \mathrm{H}_{4} \text { btec/pyz/ } \\
\mathrm{NaOH} / 2: 1: 2 \mathrm{MeOH}-\mathrm{H}_{2} \mathrm{O} \\
\text { solution at room } \\
\text { temperature }\end{array}$ & $\begin{array}{l}2002 \text { Inorg. } \\
\text { Chem. } 416161\end{array}$ \\
\hline & {$\left[\mathrm{Cu}(\right.$ btec $\left.)\left(\mathrm{H}_{2} \mathrm{O}\right)_{3}\right] \cdot 3 \mathrm{H}_{2} \mathrm{O}$} & $\begin{array}{l}\mathrm{CuCO}_{3} / \mathrm{H}_{4} \text { btec } / 1: 2 \text { in } \\
\text { water at room temperature }\end{array}$ & $\begin{array}{l}2002 \text { Eur. J. } \\
\text { Inorg. Chem. } \\
1115\end{array}$ \\
\hline $\mathrm{HC}$ & {$\left[\mathrm{Cu}(\text { btec })_{0.5} \mathrm{dmf}\right]$} & $\begin{array}{l}\text { A DMF solution of } \mathrm{H}_{4} b t c \\
(0 \cdot 5 \mathrm{mmol}) \text { was added } \\
\text { drop-wise into a methanol } \\
\text { solution of } \mathrm{CuCl}_{2} \\
(1 \mathrm{mmol}) . \text { The solution } \\
\text { left for crystallization }\end{array}$ & $\begin{array}{l}2007 \text { Z. Anorg. } \\
\text { Allg. Chem. } \mathbf{6 3 3} \\
1735\end{array}$ \\
\hline & $\begin{array}{l}{\left[\mathrm{Cu}_{2}(b p t c)\left(\mathrm{H}_{2} \mathrm{O}\right)_{2}(\mathrm{dmf})_{3}\right.} \\
\left.\left(\mathrm{H}_{2} \mathrm{O}\right)\right] \mathrm{MOF} 505\end{array}$ & $\begin{array}{l}\mathrm{H}_{4} b p t c / \mathrm{Cu}\left(\mathrm{NO}_{3}\right)_{2} \cdot 2 \cdot 5 \mathrm{H}_{2} \mathrm{O} \\
\text { in } \mathrm{DMF} / \mathrm{ethanol} / \mathrm{H}_{2} \mathrm{O} \text { at } \\
65^{\circ} \mathrm{C} \text { for } 24 \mathrm{~h}\end{array}$ & $\begin{array}{l}2005 \text { Angew. } \\
\text { Chem. Int. Ed. } \\
\mathbf{4 4} 4745\end{array}$ \\
\hline
\end{tabular}

$\left(b d c=1,3\right.$-benzenedicarboxylate, tma = benzene-1,3,5-tricarboxylate, $b t c=1,2,4$-benzene, $\mathrm{H}_{4} b t e c=1,2,4,5$-benzenetetracarboxylic acid tricarboxylate, $\mathrm{H}_{4} b p t c=3,3^{\prime}, 5,5^{\prime}$-biphenyltetracarboxylic acid) 


\section{Conclusions}

The intuitive mechanisms in terms of molecular recognition and aggregation in solution between tectons enables one to propose a structure for the critical nucleus, the high energy intermediate; this establishes the directions of possible self-assembly prognosis paving way for a rational synthesisstructure correlation. It is necessary to employ suitable experimental techniques (microscopic, spectroscopic, and other solution methods) to ascertain the interactions between molecules at higher concentrations and thus establish a link between molecular and colloidal species. Computer simulation studies are essential to gain as much information as possible on the molecular-scale interactions leading to nucleation of minute crystals.

\section{Acknowledgements}

M S, D K and J T acknowledge University Grants Commission (UGC), Department of Science and Technology (DST) and Honeywell International India Private Limited, respectively for research fellowships. AR acknowledges DST for providing continuous funding for the past two decades and infrastructural support. AR is also thankful to Professor G R Desiraju for his constant encouragement and advice.

\section{References}

1. Rao C N R and Raveau B (eds) 1998 Transition metal oxides (Weinheim: Wiley-VCH)

2. Rao C N R and Gopalakrishnan J 1997 New directions in solid state chemistry (Cambridge: Cambridge University Press)

3. Cheetham A K, Rao C N R and Feller R K 2006 Chem. Comm. 4780

4. Janiak C 2003 Dalton Trans. 2781

5. Tranchemontagne D J, Mendoza-Cortés J L, O'Keefe M and Yaghi O M 2009 Chem. Soc. Rev. 381213

6. Kitagawa S, Kitaura R and Noro S 2004 Angew. Chem. Int. Ed. $\mathbf{4 3} 2334$

7. Gopalakrishnan J 2009 J. Chem. Sci. 121235

8. Gopalakrishnan J 1995 Chem. Mater. 71265

9. Yaghi O M, O'Keeffe M, Ockwig N W, Chae H K, Eddaoudi M and Kim J 2003 Nature 423705
10. Phan A, Christian J D, Uribo-Romo F J, Knobler C B, O'Keeffe M and Yaghi O M 2010 Acc. Chem. Res. 4358

11. Longa J R and Yaghi O M 2009 Chem. Soc. Rev. 38 1213

12. Thomas J and Ramanan A 2007 Curr. Sci. 931664

13. Ramanan A and Whittingham M S 2006 Cryst. Growth Des. 62419

14. Pavani K, Ramanan A and Whittingham M S 2006 J. Mol. Str. 796179

15. Pavani K, Loftland S E, Ramanujachary K V and Ramanan A 2007 Eur. J. Inorg. Chem. 568

16. Upreti S and Ramanan A 2007 Cryst. Growth Des. 7 966

17. Thomas J and Ramanan A 2008 Cryst. Growth Des. 8 3390

18. Pavani K, Singh M, Ramanan A, Lofland S E and Ramanujachary K V 2009 J. Mol. Str. 933156

19. Thomas J, Agarwal M, Ramanan A, Chernova N and Whittingham M S 2009 Cryst. Eng. Comm. 11625

20. Singh M, Thomas J and Ramanan A 2010 Aust. J. Chem. 63565

21. Corey E J 1991 Angew. Chem. Int. Ed. Engl. 30455

22. Desiraju G R 1995 Angew. Chem. Int. Ed. 312311

23. Brunet P, Michel S and Wuest J D $1997 \mathrm{~J}$. Am. Chem. Soc. 1192737

24. Desiraju G R 2007 Angew. Chem. Int. Ed. 468342

25. Erdemer E, Lee A Y and Myerson A Y 2009 Acc. Chem. Res. 42621

26. Schüth F 2001 Curr. Opin. Sol. State and Mater. Sci. 5389

27. Novoa J J, Braga D and Addadi L (eds) 2007 Engineering of crystalline materials properties (The Netherlands: Springer)

28. Kitaigorodskii A I 1965 Acta Cryst. 18585

29. Etter M C 1990 Acc. Chem. Res. 23120

30. Millange F, Medina M I, Guillou N, Ferey G, Golden K M and Walton R I 2010 Angew. Chem. 49763

31. Davey R J, Allen K, Blagden N, Cross W I, Lieberman H F, Quayle M J, Righini S, Seton L and Tiddy G J T 2002 Cryst. Eng. Comm. 457

32. Perrin D D and Sharma V S 1966 J. Inorg. Nucl. Chem. 281271

33. Findlay A, Campbell A N and Smith N O 1951 The phase rule and its applications (New York: Dover Publications, Inc.)

34. Reddy C K, Das A and Jayaram B $2001 \mathrm{~J}$. Mol. Biol. 314619

35. Zhanga X J, Xinga Y H, Hana J, Gec M-Fa and Niu S Y 2007 Z. Anorg. Allg. Chem. 633269

36. Maciejewski M, Baiker A and Viebrock H 1993 Solid State Ionics 63-65 346

37. Fernandes C, Neves A, Bortoluzzi A J, Szpoganicz B and Schwingel E 2001 Inorg. Chem. Commun. 4354

38. LaDuca R L 2009 Coord. Chem. Rev. 2531759 